\title{
RESOLUCIÓN DEL TRIBUNAL CONSTITUCIO- NAL FEDERAL ALEMÁN. SOBRE EL ART. 217 DEL CÓDIGO PENAL ALEMÁN
}

\section{THE DECISION OF THE GERMAN FEDERAL CONSTITUTIONAL COURT. ABOUT THE ARTICLE 217 OF THE GERMAN CRIMINAL CODE}

\section{Gonzalo Dell'Orsi'}

DOI: https://doi.org/10.37767/2591-3476(2020)27

\section{Comentario a}

Urteil des Zweiten Senats vom 26. Februar 2020

Tribunal Constitucional Federal Alemán

\author{
Disponible en \\ https://bit.ly/32gxtMI
}

\section{RESUMEN:}

Con fecha 26 de febrero de 2020, la cámara segunda del Tribunal Constitucional Federal Alemán declaró la inconstitucionalidad y nulidad del art. 217 del Código Penal Alemán. Este artículo, en su redacción luego de ser modificado en el año 2015, amenaza en su primer inciso con pena privativa de la libertad a quien promoviera de manera comercial la asistencia al suicidio. En dicha oportunidad, los Magistrados entendieron y decidieron de manera conjunta sobre seis recursos de inconstitucionalidad, y concluyeron en que la norma atacada vulnera los siguientes derechos constitucionales: el derecho al libre desarrollo de la personalidad (art. 2. inc. 1 en conexión con el art. 1 inc. 1); el derecho a la libertad (art. 2 inc. 2 segunda oración en conexión con el art. 104 inc. 1); y el derecho a la libertad de trabajo (art. 12 inc. 1).

\begin{abstract}
On 26 February 2020, the second chamber of the German Federal Constitutional Court declared section 217 of the German Criminal Code unconstitutional and void. This section, as amended in 2015, threatens in its first paragraph with prisión sentence for anyone who commercially promotes assisted suicide. On that occasion, the judges considered and decided jointly on six constitutional appeals, and concluded that the rule attacked violated the following constitutional rights: the right to free personality development (article 2, paragraph 1 , in connection with article 1, paragraph 1); the right to liberty (article 2, paragraph 2, second
\end{abstract}

1 Abogado (Universidad Nacional de Córdoba); Magister en Derecho alemán y doctorando (Ludwig Maximilians Universität de Munich). Prosecretario del Superior Tribunal de Justicia de la Provincia de Tierra del Fuego. gdellorsi@gmail.com ORCID iD: https://orcid.org/0000-0002-0504-9052 
sentence in reference to article 104, paragraph 1); and the right to freedom of work (article 12 , paragraph 1$)$.

PALABRAS CLAVE: Inconstitucionalidad; Nulidad; Tribunal Constitucional Federal Alemán; Art. 217 StGB; Asistencia al suicidio.

KEY WORDS: Unconstitutionality; Nullity; German Federal Constitutional Court; Article 217 Criminal Code; Assisted suicide.

\section{Introducción}

El presente trabajo es un comentario de la Sentencia del 'Tribunal Constitucional Federal Alemán'2 (en adelante también Tribunal), de fecha 26 de febrero de 2020, mediante la cual declaró la inconstitucionalidad y nulidad del 'art. 217 del Código Penal Alemán’3 (en adelante también art. 217). El Tribunal resolvió seis recursos de inconstitucionalidad presentados por personas físicas y jurídicas, quienes alegaron verse afectadas por la norma en cuestión.

En esta inteligencia, el Tribunal analizó los reclamos de los recurrentes, sus alegados agravios a derechos fundamentales y la vinculación de estos con la norma del art. 217. Al analizar esta última, consideró el objetivo perseguido, y la proporcionalidad de la medida impuesta a tal fin, en relación con los derechos vulnerados. Esto es, por un lado, la prohibición de promover la asistencia comercial al suicidio, y por el otro, los derechos fundamentales al libre desarrollo de la personalidad, a la libertad en general y a la libertad de trabajo.

El comentario comienza con una escueta reseña del caso, donde presento la norma sobre la cual se pronunció el Tribunal, los distintos recurrentes que alegaron ver afectados sus derechos, y la forma en que el Tribunal estructuró su sentencia (I). A continuación, presento los recurrentes con sus respectivos agravios (II), para luego pasar al análisis de admisibilidad que, sobre estos, realizó el Tribunal (III). Seguidamente, presento la norma atacada, con una breve reseña sobre su origen como proyecto, el objetivo perseguido y la implicancia que efectivamente tiene (IV), y como consecuencia, la vulneración de los derechos (V). Finalmente, expongo la conclusión a la que arribó el tribunal (VI).

\section{Reseña del fallo}

En su sentencia, el Tribunal Constitucional Federal Alemán se pronuncia sobre seis recursos de inconstitucionalidad, cuyos promovedores argumentan verse afectados por la misma norma. Todos ellos se dirigen contra el artículo 217 del Código Penal Alemán, el cual luego de haber sido modificado el 3 de diciembre de 2015, amenaza con pena privativa de la libertad a quien promoviere la asistencia al suicidio con fines comerciales (Deutscher Bundestag, 2015: 2177).

Los recurrentes son variados, encontrando entre ellos: Personas que estando asociadas

2 En alemán Bundesverfassungsgericht. Todas las citas originales del alemán han sido traducidas al castellano por el autor.

3 En alemán §217 StGB (Strafgesetzbuch). 
a una asociación que presta asistencia al suicidio, desean hacer uso de tal oferta y finalizar su vida (BvR 2347/15 33); Una asociación alemana que presta asistencia al suicidio (BvR 651/16 41); Dos asociaciones que prestan asistencia al suicidio con asiento en Suiza y Alemania, y sus representantes y trabajadores (BvR 1261/16 56); Un médico especialista en medicina interna (BvR 1593/16 71); Médicos activos en cuidados paliativos de pacientes internos y externos (BvR 2354/16 75); Y por último un grupo de seis personas, entre las que se encuentran pacientes, médicos y un abogado (BvR 2527/16 81).

El Tribunal estructura la sentencia de la siguiente manera: Comienza con un informe del caso, en donde hace una introducción, establece el objeto del proceso y la normativa a seguir. Compara la normativa de otros Estados relacionada al tema, y analiza cada uno de los seis recursos constitucionales. Seguidamente analiza la toma de postura respecto al tema por parte de distintos organismos y los dichos en la audiencia oral. En un segundo y tercer punto analiza respectivamente la admisibilidad de los recursos y su fundamentación. Finalmente, en un cuarto punto, procede a su pronunciamiento. En este, el Tribunal declara la inconstitucionalidad del art. 217 y su nulidad.

\section{Los recurrentes y sus agravios}

Como ya se adelantó, los recursos presentados y sobre los que se expidió el Tribunal en su sentencia son seis. A continuación, presentaré cada uno de ellos, con sus respectivos agravios.

\section{Recurso Constitucional BvR $2347 / 15$}

Los recurrentes aquí son dos personas (recurrentes I. 1. y I. 2) que experimentan una suerte de muerte agónica a raíz de una enfermedad incurable. Debido a ello y con el fin de terminar con su vida, ambos celebraron -con anterioridad a la modificación del art. 217- un contrato con una asociación que brinda asistencia comercial al suicidio (recurrente II.) (Sentencia, párr. 34).

Ambos alegan que, debido a la prohibición impuesta por la norma, ven afectado su derecho al suicidio, derivado del derecho al libre desarrollo de la personalidad en virtud del art. 2 inc. 1 de la 'Ley fundamental para la República Federal Alemana'4 (en adelante Constitución), en conexión con el art. 1 inc. 1 del mismo cuerpo normativo (Sentencia, párr. 35). Consideran que el derecho de autodeterminación sobre la propia muerte incluye no solo el momento, sino también la forma de la muerte, y esto incluye la asistencia de terceros (Sentencia, párr. 36). Asimismo, los recurrentes consideran que esta restricción al derecho de la autodeterminación es una intervención excesiva, y no se encuentra constitucionalmente justificada bajo la intención de proteger la vida, perseguida por el legislador (Sentencia, párr. 38).

\section{Recurso Constitucional BvR $651 / 16$}

La recurrente aquí es una asociación registrada en Alemania (recurrente II.), que previo a la entrada en vigor del art. 217, ofrecía asistencia para el suicidio, servicios de asesoramiento en la redacción y aplicación de testamentos, y asistencia y atención médica preventiva (Sentencia, párr. 42). Una vez vigente la nueva norma, la asociación se vio obligada a suspender el ofrecimiento del servicio de asistencia al suicidio en Alemania, y por ello, considera que esta la afecta en su derecho fundamental derivado del art. 9 inc. 1 de la Constitución (Sentencia, párr. 45 y 46). 
La recurrente sostiene que la protección del art. 9 inc. 1 de la Constitución -además de la libre determinación sobre la propia organización-, comprende el proceso para la adopción de decisiones y la realización de sus actividades, incluidas las específicas para las cuales ésta fue conformada (Sentencia, párr. 47). La prohibición de la promoción del suicidio por motivos comerciales interfiere en el proceso interno de adopción de decisiones de la asociación, y en el desarrollo regular de sus actividades establecidas de manera estatutaria (Sentencia, párr. 48).

\section{Recurso Constitucional BvR 1261/16}

Los recurrentes aquí (Recurrentes III. 1 a III. 6) son dos asociaciones que brindan servicio de eutanasia con sede en Suiza y Alemania, y sus respectivos representantes y empleados.

La recurrente III. 1 es una asociación constituida en Suiza, y igual que la recurrente II., las actividades que realiza -si bien se limitan al territorio suizo- abarcan desde servicios de asesoramiento general relacionados a la atención y protección de pacientes, hasta la asistencia al suicidio (Sentencia, párr. 58). La recurrente III. 2 es una asociación, constituida en Alemania, cuyas actividades consisten en servicios de fortalecimiento de la autodeterminación, como así también el acompañamiento en la asistencia al suicidio. Sin embargo, ya antes de la entrada en vigor del art. 217, su actividad respecto a la asistencia al suicidio se limitaba a proporcionar a sus miembros un acuerdo de cooperación con la asociación hermana suiza (recurrente III. 1) (Sentencia, párr. 63). Con la entrada en vigor de la norma, la asociación cesó en su práctica de mediación (Sentencia, párr. 64). Los recurrentes III. 3 y III. 4 son dos personas que ocupan cargos directivos en las asociaciones recurrentes. El primero de ellos es fundador de ambas asociaciones y secretario general de la asociación suiza. El segundo es miembro fundador de la asociación alemana y su segundo presidente (Sentencia, párr. 65). La recurrente III. 5 asesora a los miembros de ambas asociaciones recurrentes en todos los asuntos relacionados con la asistencia al suicidio y los acompaña personalmente durante la ejecución del suicidio (Sentencia, párr. 66). El recurrente III. 6 es cofundador de la asociación alemana (recurrente III. 2) y asesora como abogado a los representantes, empleados y miembros de las asociaciones recurrentes III. 1 y III. 2. Esta actividad incluía -antes de la entrada en vigor del art. 217- el asesoramiento individual sobre las posibilidades fácticas y jurídicas de la asistencia al suicidio en Suiza y la mediación entre las dos asociaciones (Sentencia, párr. 67).

Las asociaciones alegan que desde la entrada en vigor del art. 217, su actividad en la esfera de la asistencia al suicidio está castigada con multa según el art. 30 inc. 1 Nr. 1 OWiG 5 . Esta situación incluye a la asociación con sede social en Suiza, toda vez que su cooperación con su hermana alemana sería considerada como complicidad en la comisión de tipo delictivo establecido en el art. 217 inc. 1 (Sentencia, párr. 69).

Los representantes, empleados y asesores de las asociaciones recurrentes invocan su libertad de conciencia (art. 4 inc. 1 var. 2 de la Constitución), y en la medida en que no tienen nacionalidad alemana, invocan de manera subsidiaria la protección del art. 2 inc. 1 de la Constitución (Sentencia, párr. 70).

\section{Recurso Constitucional BvR 1593/16}

El recurrente aquí es un médico especialista en medicina interna (recurrente IV.), que 
atiende a pacientes que padecen enfermedades mortales y en el ejercicio de su profesión, asistió en varias oportunidades y siempre de manera gratuita al suicidio (Sentencia, párr. 71). Considera que el art. 217 afecta su libertad de conciencia (art. 4 inc. 1 var. 2 de la Constitución) y su libertad de trabajo (art. 12 inc. 1 de la Constitución) (Sentencia, párr. 72).

\section{Recurso Constitucional BvR 2354/16}

Los recurrentes aquí (recurrentes V. 1 a V. 4) son médicos, activos en cuidados paliativos. El recurrente V. 1 es médico especialista en medicina paliativa y jefe de un equipo, que proporciona cuidados paliativos a pacientes gravemente enfermos. La recurrente $V .2$ es médica especializada en medicina interna y se desempeña como médica jefa del departamento de medicina paliativa de una clínica. La recurrente $V$. 3 es médica especialista en medicina general con calificación adicional con acupuntura y medicina paliativa. El recurrente V. 4 es médico, y también se desempeña en cuidados paliativos. Los cuatro recurrentes se ocupan de pacientes gravemente enfermos -hospitalizados o ambulatorios-, y en su trabajo se enfrentan repentinamente al deseo de ayudar al suicidio (Sentencia, párr. 76).

Consideran -al igual que el recurrente IV.- que, debido a su vaguedad, el art. 217 no garantiza la impunidad de la asistencia médica al suicidio practicada de forma restrictiva (Sentencia, párr. 77). Sostienen que, para evitar los riesgos de responsabilidad penal, se ven obligados a ejercer su profesión actuando en contra del interés del paciente y de su autodeterminación, y argumentan por ello verse afectados en sus derechos fundamentales de libertad de conciencia y de trabajo, en virtud de los arts. 4 inc. 1 var. 2 y 12 inc. 1 de la Constitución (Sentencia, párr. 78).

\section{Recurso Constitucional BvR 2527/16}

Los recurrentes aquí son cinco (recurrentes VI. 1 a VI. 5). El primero de ellos, recurrente VI. 1, es un médico que hasta la entrada en vigor del art. 217, brindo ayuda a enfermos terminales y pacientes gravemente afectados para suicidarse. El recurrente falleció en abril del 2019 (Sentencia, párr. 82). La recurrente VI. 2 es una médica clínica que ejerce su profesión en Suiza. Fue asesora de la asociación recurrente en el punto III. 1, y en 2011 fundó su propia fundación para acompañamiento al suicidio. La recurrente examinaba la capacidad de adoptar decisiones y la gravedad de su solicitud de asistencia de personas en Alemania, para luego acompañarlas a Suiza, donde se prestaba la asistencia al suicidio. Con la entrada en vigor del art. 217, cesó sus actividades en Alemania (Sentencia, párr. 83). El recurrente VI. 3 es un abogado especializado en derecho sanitario y de atención médica, que asesoraba a clientes sobre cuestiones jurídicas relacionadas con la asistencia al suicidio, y acompañaba a personas gravemente enfermas a Suiza, para que pudieran finalizar su vida con asistencia. Con la entrada en vigor del art. 217 cesó en su actividad de asesoramiento y acompañamiento (Sentencia, párr. 84).

Los recurrentes VI. 2 y VI. 3 sostienen que se les impide ayudar al suicidio. Según ellos, esto iría en detrimento de su libertad de conciencia y de trabajo, y subsidiariamente de su libertad de acción general (Sentencia, párr. 86).

Los recurrentes VI. 4 y VI. 5 eran cónyuges que buscaron sin éxito la asistencia para el suicidio. La recurrente VI. 4 falleció. El recurrente VI. 5 sostiene, al igual que los recurrentes I. 1 y I. 2, estar restringido por el art. 217 en su decisión autónoma sobre las modalidades de su muerte. Se le hace imposible de hecho utilizar los servicios de un asistente 
profesional para el suicidio, y se le niega así lo que el considera una forma humana de suicidio. Considera que la protección fundamental de esa decisión deriva tanto del derecho al libre desarrollo de la personalidad (art. 2 inc. 1 en conexión con el art. 1 inc. 1 de la Constitución) y del derecho a la vida del art. 2. inc. 2 primera oración de la Constitución) (Sentencia, párr. 87).

\section{Admisibilidad de los recursos}

El tribunal analizó la admisibilidad de los distintos recursos en razón a sus particularidades.

1. En primer lugar, consideró resueltos los recursos presentados por VI. 1 y VI. 4, debido a la muerte de ambos recurrentes.

2. Luego analizó el recurso presentado por la recurrente III. 1, y lo declaró inadmisible por tratarse de una asociación para asistencia al suicidio constituida en Suiza. En su calidad de persona jurídica no nacional, la recurrente carece de capacidad jurídica para presentar una solicitud invocando derechos materiales fundamentales. En este sentido, el art. 19 inc. 3 de la Constitución establece que los derechos básicos se aplican únicamente a las entidades jurídicas nacionales. Las personas jurídicas extranjeras, solo pueden invocar los derechos procesales básicos previstos en el art. 101 inc. 1 oración 2 y art. 103 inc. 1 de la Constitución (Sentencia, párr. 184).

3. Por último, el Tribunal declaró admisibles los recursos restantes, por considerar que los recurrentes pueden ampararse en la protección de derechos fundamentales, y mostraron de qué modo la norma atacada afectó su derecho o produjo un perjuicio. Para el análisis, el Tribunal los subdividió en tres grupos.

\section{a. Los recurrentes I. 1, I. 2 y VI. 5}

El Tribunal consideró que los recurrentes aquí nombrados, que desearon recurrir a la asistencia profesional para el suicidio en un momento oportuno, pueden alegar que a través del art. 217 ven lesionado un derecho fundamental (art. 93 inc. 1 Nr. 4. a, de la Constitución', art. 90 inc. 1 BVerfGG7) (Sentencia, párr. 194). El Tribunal refirió que, si bien ellos no son los destinatarios de la prohibición establecida en la norma del art. 217, esta los afecta de manera indirecta, toda vez que imposibilita el acceso a la asistencia al suicidio que ellos necesitan (Sentencia, párr. 195 y 196).

b. Los recurrentes II. y III. 2

Los recurrentes aquí son personas jurídicas que ofrecen asistencia al suicidio y tienen asiento en Alemania. Según el art. 19 inc. 3 de la Constitución ellas pueden hacer valer el derecho general a la libertad de acción con base en el art. 2 inc. 1 del mismo cuerpo normativo. El Tribunal entendió que si bien estas, como personas jurídicas, no están sujetas a responsabilidad de acuerdo con el art. 217, pueden estarlo en virtud del art. 30 inc. 1 Nr. 1 OWiG. No obstante, los miembros de las asociaciones sí estarían sujetos al reproche en virtud del art. 217 (Sentencia, párr. 197). 
c. Los recurrentes III. 3, III. 5 y VI. 2

Los miembros de una asociación para la asistencia al suicidio en Suiza, pero cuyas actividades se realizaban en Alemania, pueden -como ciudadanos suizos- alegar ver afectado su derecho general a la libertad de acción (art. 2 inc. 1 de la Constitución), y en relación con la amenaza del castigo para ciudadanos no alemanes, en su garantía a la inviolabilidad de la libertad (art. 2 inc. 2 segunda oración en conexión con el art. 104 inc. 1 de la Constitución), como así también en su derecho al libre desarrollo de la personalidad (art. 2 inc. 1 en conexión con el art. 1 inc. 1 de la Constitución) (Sentencia, párr. 198).

\section{Normativa en conflicto}

La norma, mediante la cual los recurrentes se ven afectados es el art. 217 del Código Penal Alemán, en su redacción luego de la modificación introducida por la "Ley para la punibilidad de la promoción comercial al suicidio"8, aprobada el 3 de diciembre de 2015 por la cámara baja del Parlamento Alemán (Bundestag) y vigente desde el 10 de diciembre del mismo año (Sentencia, párr. 10). Esta cuenta de dos artículos: el primero modifica al art. 217 del Código Penal, y el segundo establece que la ley entra en vigor el día siguiente a su publicación (Gesetz zur Strafbarkeit der geschäftsmäßigen Förderung der Selbsttötung, 2015). El art. en cuestión quedó redactado de la siguiente manera:

"Art. 217 Promoción comercial del suicidio (1) El que, con intención de promover el suicidio de otra persona, otorgue, procure o medie en la oportunidad de hacerlo de manera comercial, será castigado con una pena de prisión de hasta tres años o una multa. (2) Los participantes estarán exentos de castigo si no actúan con fines comerciales y son parientes o allegados de la otra persona a que se refiere el inciso 1." (§ 217 StGB).

En el proceso legislativo se sometieron a discusión y votación 4 proyectos, con diferentes enfoques sobre la posible reglamentación del deseo de finalización autodeterminada de la propia vida. Estos fueron: 1. Proyecto sobre la criminalización de la promoción comercial del suicidio; 2 . Proyecto sobre la terminación de la vida supervisada médicamente; 3. Proyecto sobre la impunidad de la ayuda al suicidio; y 4. Proyecto sobre la participación criminal en el suicidio. El proyecto aprobado fue el primero de ellos (BDTrucks 18/5373).

Según el proyecto, en el planteo del problema se establece que la impunidad del suicidio y la participación en él no deben cuestionarse. Sino que es necesario regular las ofertas de tipo comercial, cuando estas generan que la asistencia para el suicidio se vea como una opción de tratamiento normal y pueda tentar a las personas a quitarse la vida. $Y$ continúa diciendo que "el objetivo del presente proyecto de ley es evitar que el suicidio asistido se convierta en un servicio de atención de la salud. En Alemania, hay un número creciente de casos en que asociaciones o personas conocidas por el público se ofrecen regularmente a ayudar al suicidio, por ejemplo, concediendo, procurando u organizando el suministro de una droga letal. Esto amenaza con provocar una 'normalización' social, un 'efecto de habituación' a esas formas organizadas de suicidio asistido. En particular, las personas mayores y/o enfermas pueden sentirse tentadas a cometer un suicidio asistido o incluso sentirse directa o indirectamente presionadas. Sin la disponibilidad de tales ofertas, no considerarían, y mucho menos tomarían tal decisión. Por consiguiente, esas acciones, que no tienen necesariamente una orientación comercial, pero que son un tipo de negocio, es decir que están concebidas 
para repetirse, también deben ser contrarrestadas por los medios del derecho penal a fin de proteger la libre determinación y el derecho fundamental a la vida. El proyecto no penaliza de manera explícita la asistencia para el suicidio, el que en casos concretos de situaciones graves está garantizado. Una prohibición absoluta de la asistencia al suicidio (como sucede en algunos países de Europa) es políticamente indeseable y difícilmente sería compatible con las bases fundamentales de la Constitución. Asimismo, en una disposición separada se aclara que los familiares $u$ otras personas cercanas al suicida no son susceptibles de enjuiciamiento si son meramente participantes en el delito y no actúan ellos mismos de manera comercial" (Deutscher Bundestag, 2015: 2 y 3).

Con ello se observa que la norma no persigue indagar el principio de impunidad del suicidio y la participación en él, sino intervenir de manera correctiva cuando las ofertas comerciales de asistencia al suicidio ponen en peligro la autodeterminación y la vida.

Sin embargo, sobre este proyecto tuvo oportunidad de expresarse un colectivo de académicos (141 profesores y profesoras de derecho penal), en cuya declaración conjunta de fecha 15 de abril de 2015, consideraron -entre otras cosas- que la eutanasia es desde hace mucho tiempo legal, que las personas con deseo de morir necesitan cuidados y apoyos especiales, y que la penalización del suicidio asistido haría más difícil o imposible que los médicos proporcionaran ayuda profesional, toda vez que estos se apartarían por temor a la responsabilidad penal (Stellungnahme deutscher Strafrechtsleherinnen und Strafrechtslehrer, 2015). Sostuvieron asimismo que el objetivo debe ser llegar al mayor número posible de personas con deseos de morir, a fin de reducir el número de suicidios en Alemania, y en este sentido el derecho penal no es el medio adecuado para ello (SteIlungnahme deutscher Strafrechtsleherinnen und Strafrechtslehrer, 2015).

El Tribunal observó que con esta redacción del art. 217, se penaliza por primera vez desde el año 1871 (año de la introducción de un sistema uniforme de derecho penal en Alemania), la participación de una persona en el suicidio de otra, actuando esta última bajo su propia responsabilidad (Sentencia, párr. 16). Asimismo, remarcó que el actual sistema de justicia penal no castiga el suicidio, razón por la cual, la asistencia para este (como participación no dirigida) por un actor en un suicidio autoinflingido, también se encuentra exenta de castigo (Sentencia, párr. 23). Por otro lado, el derecho alemán ya contiene una distinción entre el homicidio punible a petición (art. 216 CP), y la ayuda al suicidio impune (suicidio asistido), configurando la distinción entre ambos la determinación de "quién ha dominado realmente el hecho que lleva a la muerte, es decir, quien lleva a cabo la acción que conduce directamente a la muerte" (Meyer-Köring).

Corresponde asimismo observar que, la norma del art. 217 no amenaza con castigo actos de ayuda de tipo comercial en el sentido del 'art. 27 del Código Penal (Behilfe)' quiriendo para ello al menos el comienzo de la fase de ejecución, sino que va más allá en su concepción como un delito abstracto de puesta en peligro (Meyer-Köring). Así, es punible la concesión o mediación de una oportunidad de suicidarse como un acto que pone en peligro la vida en abstracto, sin ser necesario para ello ni siquiera un intento de ejecución. 


\section{La vulneración de derechos}

En virtud de las diferentes características de los recurrentes, el Tribunal analizó los derechos vulnerados por la norma en cada uno de ellos, agrupándolos según sus condiciones. De esta manera, el Tribunal concluyó en que: el art. 217 del Código Penal Alemán vulnera a los recurrentes I. 1 I. 2 y VI. 5 en el derecho al libre desarrollo de la personalidad (art. 2 inc. 1 de la Constitución en conexión con el art. 1 inc. 1 del mismo cuerpo normativo); Los recurrentes que desean prestar asistencia para el suicidio en el marco de su actividad profesional y tienen nacionalidad alemana, ven vulnerado su derecho fundamental a la libertad de trabajo (art. 12 inc. 1 de la Constitución) y su libertad de acción (Art. 2 inc. 1 de la Constitución); Los recurrentes III. 3 a III. 6; IV; V. 1 a V. 4; VI. 2 y VI. 3, ven vulnerado a través de la amenaza de pena privativa de la libertad, su derecho a la inviolabilidad de la libertad (Art. 2 inc. 2 segunda oración de la Constitución, en conexión con el Art. 104 inc. 1 del mismo cuerpo normativo); Los recurrentes II. y III. 2, alcanzados por una multa según el art. 30 inc. 1 Nr. 1 OWiG, ven afectado su derecho de libertad de acción (art. 2 inc. 1 de la Constitución) (Sentencia, párr. 201).

1. Los recurrentes I. 1 I. 2 y VI. 5 son personas físicas que decidieron finalizar su vida, y quisieron para ello hacer uso de la asistencia ofrecida por distintas asociaciones. Aquí es necesario aclarar que, si bien ellos no son los destinatarios directos de la amenaza establecida por la norma del art. 217, se ven afectados de manera indirecta, toda vez que esta invade el derecho general al libre desarrollo de la personalidad. El derecho de una persona -capaz de libre autodeterminación y responsabilidad personal- de quitarse la vida, se encuentra contenido en el derecho al libre desarrollo de la personalidad (art. 2 inc. 1 en conexión con el art. 1 inc. 1 de la Constitución).

Art. 1 de la Constitución: "(1) La dignidad del hombre es inviolable. Respetarla y protegerla es obligación de todas las autoridades del Estado. (2) El pueblo alemán reconoce, en consecuencia, los derechos inviolables e inalienables del hombre como fundamento de toda comunidad humana, de la paz y de la justicia en el mundo. (3) Los derechos fundamentales que se enuncian a continuación vinculan al Poder Legislativo, al Poder Ejecutivo y a los tribunales a título de derecho directamente aplicable." (Artikel 1 des Grundgesetzes für die Bundesrepublik Deutschland).

Art. 2 de la Constitución: "(1) Cada uno tendrá derecho al libre desarrollo de su personalidad, en tanto no vulnere los derechos de otro y no atente al orden constitucional o a la ley moral. (2) Cada uno tendrá derecho a la vida y a la integridad física. La libertad de la persona es inviolable. Estos derechos sólo podrán verse afectados en virtud de una ley." (Artikel 2 des Grundgesetzes für die Bundesrepublik Deutschland).

En esta inteligencia, el Tribunal observó que el respeto y la protección de la dignidad humana son principios fundamentales del orden constitucional, que entiende al ser humano como una persona capaz de determinarse de manera autónoma y de asumir responsabilidades personales (Sentencia, párr. 205). Esta idea de autodeterminación, tiene sus raíces en la dignidad humana, cuya inviolabilidad garantiza el art. 1 inc. 1 de la Constitución.

Siguiendo con este razonamiento, el Tribunal entendió que el derecho al libre desarrollo de la personalidad como expresión de la autonomía personal incluye el derecho a la muerte autodeterminada, lo que consecuentemente incluye al suicidio. Sobre ello, dijo 
que la "decisión de finalizar su propia vida se refiere a cuestiones fundamentales de la existencia humana y afecta a la identidad e individualidad del hombre como ninguna otra decisión" (Sentencia, párr. 209). En este sentido, agregó que no es correcto sostener que quien incurre en suicidio está renunciando a su dignidad, sino al contrario, que la decisión autodeterminada de finalizar la vida es una expresión directa de la idea del desarrollo autónomo, inherente a la dignidad humana, y como tal, aunque sea la última, es una expresión de dignidad (Sentencia, párr. 211).

Ahora bien, -como ya se adelantó- la vulneración al derecho de finalizar su propia vida, protegido por el art. 2 inc. 1 en conexión con el art. 1 inc. 1 de la Constitución, se realiza de manera indirecta. Ello se debe a que los interesados solo pueden llevar adelante y ejecutar tal decisión con la ayuda de terceros, particularmente médicos. En este sentido, el Tribunal entendió que "si el ejercicio de un derecho fundamental depende de la participación de terceros, y de esta manera el libre desarrollo de la personalidad depende de la participación de otra persona, el derecho fundamental lo protege también de ser restringido por una prohibición a terceros que ofrezcan apoyo en el contexto de su libertad" (Sentencia, párr. 213).

2. En relación con los demás recursos, el Tribunal entendió que el art. 217 contiene una limitación inconstitucional a la libertad de profesión del art. 12 inc. 1 de la Constitución, subsidiariamente con el derecho general a la libertad de acción del art. 2 inc. 1 de la Constitución. La disposición vulnera también la garantía de inviolabilidad de la libertad, según el art. 2 inc. 2 segunda oración en conexión con el art. 104 inc. 1 de la Constitución, toda vez que, como personas físicas, los recurrentes son destinatarios de la amenaza de privación de la libertad (Sentencia, párr. 332). Los recurrentes II. y III. 2, en su calidad de personas jurídicas, ven afectado su derecho fundamental del art. 2 inc. 1 de la Constitución, en virtud de la amenaza de multa según el art. 30 inc. 1 Nr. 1 OWiG (Sentencia, párr. 333).

El Tribunal sostuvo que, los médicos y abogados recurrentes de nacionalidad alemana (III. 6, IV, V. 1 a V. 4 y VI. 3), si bien no ven afectada su libertad de consciencia (art. 4 inc. 1 Var. 2 de la Constitución), ven afectado su derecho fundamental a la libertad de trabajo (art. 12 inc. 1 de la Constitución) (Sentencia, párr. 309 y 310).

Art. 12 de la Constitución: "(1) Todos los alemanes tendrán derecho a escoger libremente su profesión, su puesto de trabajo y su centro de formación, si bien el ejercicio de las profesiones podrá ser regulado por la ley o en virtud de una ley. (2) Nadie podrá ser compelido a realizar un trabajo determinado, salvo en el ámbito de un servicio público obligatorio de tipo convencional y general e igual para todos. (3) Solo en virtud de sentencia judicial de privación de libertad serán lícitos los trabajos forzados." (Artikel 12 des Grundgesetzes für die Bundesrepublik Deutschland).

Para el caso de la recurrente VI. 2 (médica con nacionalidad suiza), los recurrentes II. y III. 2 (asociaciones alemanas) y los recurrentes III. 3 a III. 5 (sus representantes y empleados), el Tribunal sostuvo que no ven afectados derechos especiales de libertad (los alegados derechos a la libertad de trabajo, y de asociación -arts. 12 inc. 1 y 9 inc. 1 de la Constitución) sino que pueden reclamar subsidiariamente por su derecho general a la libertad de acción del art. 2 inc. 1 de la Constitución (Sentencia, párr. 313).

Por otro lado, el Tribunal sostuvo que, con la amenaza de una pena privativa de la libertad, la prohibición de la promoción comercial del suicidio vulnera a los recurrentes III. 3 
a III. 6, IV, V. 1 a V. 4, VI. 2 y VI. 3 (personas físicas), en su garantía a la inviolabilidad de la libertad del art. 2 inc. 2 segunda oración en conexión con el art. 104 inc. 1 de la Constitución (Sentencia, párr. 332).

Art. 104 de la Constitución "(1) La libertad personal sólo se podrá limitar en virtud de una ley formal y con observancia de las formalidades prescriptas por ella. Ningún detenido podrá ser maltratado física ni moralmente. (2) Sólo el juez podrá pronunciarse sobre la procedencia y continuación de una privación de libertad. En todo supuesto de privación de libertad sin mandamiento judicial se deberá obtener sin demora una decisión judicial. La policía no podrá por su propia autoridad mantener detenido a nadie más allá de la expiración del día siguiente al de la detención. La reglamentación de este precepto se hará por ley. (3) Toda persona detenida preventivamente por sospecha de acción punible deberá ser llevada ante el juez al día siguiente, a más tardar, de la detención, y el juez deberá comunicar al detenido los motivos de la detención, interrogarle y darle oportunidad para que formule objeciones. El juez deberá asimismo y sin demora dictar auto razonado y escrito de prisión o disponer la puesta en libertad. (4) De toda resolución judicial sobre privación de libertad o continuación de esta se deberá dar cuenta sin demora a un familiar del detenido o a una persona de su confianza." (Artikel 104 des Grundgesetzes für die Bundesrepublik Deutschland).

Por último, el Tribunal entendió que una posible multa debido a la punibilidad de la asistencia comercial al suicidio según el art. 30 inc. 1 Nr. 1 OWiG afecta a los recurrentes II. y III. 2 en su derecho fundamental del art. 2 inc. 1 de la Constitución, del cual deriva el derecho a no ser injustamente condenado a pagar una multa (Sentencia, párr. 333).

Art. 30 inc. $1 \mathrm{Nr} .1$ OWiG "Multa a las personas jurídicas y asociaciones de personas (1) A quien: Nr. 1. Como órgano representativo de una persona jurídica o como miembro de dicho órgano (...) comete un delito o una infracción administrativa, infringe las obligaciones que incumben a la persona jurídica o a la asociación de personas o enriquece a la persona jurídica $o$ a la asociación de personas, se le puede imponer una multa." (§ 30 Abs. 1 Nr. 1 des Gesetzes über Ordnungswidrigkeiten).

\section{Conclusión del Tribunal}

El Tribunal determinó que el objetivo de la norma es legítimo, toda vez que esta se orienta a proteger la autodeterminación del individuo sobre su vida, y con ello, el derecho fundamental a la vida. Esto es, en el caso concreto, la protección de la autonomía de decisión de las personas dispuestas a suicidarse, frente a influencias que pongan en peligro esa autonomía.

Con la norma del art. 217 el legislador partió de la suposición de que la oferta de asistencia para el suicidio de tipo comercial entraña un peligro para la libre determinación en la decisión de poner fin a la propia vida y pretendió, en consecuencia, evitar que el suicidio asistido se convierta en un servicio de atención de salud, que pueda tentar a las personas a quitarse la vida. Así, con este objetivo, el legislador dio cumplimiento a un deber estatal de protección fundado en la Constitución, motivo por el cual, el objetivo no puede ser objetado constitucionalmente (Sentencia, párr. 236).

Sin embargo, pese a perseguir un objetivo legítimo, la norma no supera el principio de proporcionalidad. En función a este principio, una norma que restringe derechos fundamentales debe ser adecuada y necesaria para alcanzar los objetivos legítimos persegui- 
dos, y las restricciones que implica deben ser proporcionales (Sentencia, párr. 223). En este sentido, el Tribunal observó que, las restricciones a la libertad individual sólo son apropiadas si el nivel de la carga que pesa sobre el individuo sigue siendo razonablemente proporcional a los beneficios que se derivan para terceros (Sentencia, párr. 263).

Como se observa, en el presente caso las restricciones a la libertad impuestas por el art. 217 del Código Penal exceden la razonable proporcionalidad que debería guardar con el beneficio perseguido. La amenaza impuesta por la norma tiene como consecuencia que el derecho al suicidio -como manifestación del derecho a la muerte autodeterminada- se vea imposibilitado. Por ello, el Tribunal entendió que, si bien la norma persigue un objetivo legítimo de salud pública, la prohibición que implica es desproporcional.

Ello nos muestra que la legitimidad del fin perseguido por el legislador en una norma es condición necesaria para su adecuación al sistema normativo, pero no suficiente. El legislador debe observar el principio de proporcionalidad, mediante el cual se procura un equilibrio entre el fin perseguido y los derechos posiblemente vulnerados por la medida impuesta.

Asimismo, si bien el Tribunal entendió que el alto rango constitucional de los intereses jurídicos de la autonomía y de la vida, que el art. 217 pretende proteger, pueden -en principio- legitimar el uso del derecho penal (Sentencia, párr. 267), en el presente caso el uso de esa rama del derecho excede la protección de la autonomía del individuo, toda vez que, en lugar de protegerla la imposibilita.

De esta forma, el Tribunal concluyó en que la norma del art. 217 del Código Penal Alemán, en su redacción luego de la modificación del año 2015, no es susceptible de una interpretación conforme a la Constitución, por lo que declaró su inconstitucionalidad y nulidad.

Corresponde asimismo observar una última apreciación del Tribunal en su sentencia. Este señaló que de la inconstitucionalidad de este artículo no se deriva que el legislador deba abstenerse totalmente de regular la asistencia al suicidio. Sino que, al hacerlo, debe observar el mandato de proteger la autonomía de la decisión, y esta regulación debe ser constitucionalmente inobjetable (Sentencia, párr. 338). Entiendo esta apreciación como una especie de llamado de atención del Poder Judicial al Poder Legislativo, no tanto en la modalidad de la tarea legislativa, pero sí en la necesidad e importancia de contar -para esta temática- con una reglamentación acorde al orden político y constitucional. 


\section{REFERENCIAS BIBLIOGRÁFICAS}

- BverfG. (2020). Beschluss des Zweiten Senats vom 26. Februar 2020 - 2 BvR 2347/15, 2 BvR 651/16, 2 BvR 1261/16, 2 BvR 1593/16, 2 BvR 2354/16, 2 BvR 2527/16. Disponible en: www.bundesverfassungsgericht.de

- Deutscher Bundestag. (2015). BDTrucks 18/5373. Entwurf eines Gesetzes zur Strafbarkeit der geschäftsmäßigen Förderung der Selbsttötung. Disponible en: www.bundestag.de

- Deutscher Bundestag. (2015). Gesetz zur Strafbarkeit der geschäftsmäßigen Förderung der Selbsttötung. Disponible en: www.bundesgesetzblatt.de

- Gesetz über das Bundesverfassungsgericht (BverfGG). Disponible en: https://www.gesetze-im-internet.de/bverfgg/

- Gesetz über Ordnungswidrigkeiten (OWiG) Disponible en: https://www.gesetze-im-internet.de/owig_1968/

- Geschäftsmäßige Förderung der Selbsttötung. Meyer-Köring. 21-12-2015. Disponible en: https://www.meyer-koering.de/meldungen/2175

- Grundgesetz für die Bundesrepublik Deutschland (GG) Disponible en: https://www. gesetze-im-internet.de/gg/

- Stellungnahme deutscher Strafrechtslehrerinnen und Strafrechtslehrer zur geplanten Ausweitung der Strafbarkeit der Sterbehilfe. 15-04-2015. Disponible en: https://idw-online.de/de/attachmentdata43853.pdf

- Strafgesetzbuch für die Bundesrepublik Deutschland (StGB) Disponible en: https:// www.gesetze-im-internet.de/stgb/ 